\title{
Peripheral nerve functions in chronic alcoholic patients on disulfiram: a six month follow up
}

\author{
Sarala K Palliyath, Barry D Schwartz, Linda Gant
}

\begin{abstract}
The peripheral nerve functions of chronic alcoholic patients were studied clinically and electrophysiologically before they were placed on disulfiram (Antabuse). The evaluations were repeated while they were treated with $250 \mathrm{mg}(\mathrm{n}=33)$ and $125 \mathrm{mg}(\mathrm{n}=9)$ of disulfiram for one, three and six months. The data were compared with that of 24 untreated chronic alcoholic patients. None of the patients developed overt symptoms of peripheral neuropathy during the period of study. The patients on $250 \mathrm{mg}$ disulfiram showed a significant decline in several components of the peripheral nerve functions, but no significant electrophysiological abnormalities were noted in patients taking $125 \mathrm{mg}$ of disulfiram. Interestingly, the control group showed a significant electrophysiological improvement during the same period of observation.
\end{abstract}

Disulfiram (Antabuse) has been widely used in the rehabilitation of chronic alcoholic patients for more than forty years. Although peripheral neuropathy (PN) as a complication of disulfiram had been mentioned by Child et al in 1951, the first established case report of disulfiram neuropathy was described by Charatan in $1953 .^{2}$ Awareness of this toxicity of disulfiram to peripheral nerves has resulted lately in a surge of anecdotal reports of disulfiram neuropathy. ${ }^{3-9}$ However, most of these reported patients were not evaluated for asymptomatic alcoholic neuropathy before treatment with disulfiram. In addition, some of these patients had well-documented alcohol disulfiram reaction, ${ }^{50-13}$ diagnosis of cirrhosis of the liver ${ }^{14}$ and some were on concomitant neuroleptics. ${ }^{1516}$ Hence, it is difficult to establish the extent of the direct effect of disulfiram on peripheral nerves in these patients. In experimental conditions, however, a toxic neuropathy has been shown to occur in rats while on $250 \mathrm{mg}$ of disulfiram. ${ }^{17}$ In a previous pilot study on 15 chronic alcoholic patients treated with $250 \mathrm{mg}$ of disulfiram for three months we noted asymptomatic decline in peripheral nerve functions. ${ }^{18}$ The present report is an extension of our previous study on a new group of chronic alcoholic patients on disulfiram and with a matched control group of voluntarily abstinent chronic alcoholic patients without drug therapy. They were studied for six months.

\section{Patients and methods}

The control group and the disulfiram group were selected from the alcohol rehabilitation unit. The patients were interviewed within the first week of admission to explain the details of the study. Those who were willing to participate as either controls or as treatment group were asked to sign a consent. The choice of participation in the treatment group was voluntary; however, occasionally it was partly influenced by the primary care physician. Thus it was difficult to recruit an equal number of controls, as most of the patients preferred to take disulfiram to maintain abstinence. A very strict selection criteria was followed. Clinical and appropriate laboratory evaluations were done to exclude those who had diseases which can potentially cause peripheral neuropathy, that is, diabetes mellitus, malnutrition, collagen vascular diseases, liver diseases and systemic malignancy. Drug abuse, non-compliance and disulfiram treatment in the past were also considered as exclusion criteria. Eighty-five patients on disulfiram and 35 controls entered the study. Both groups were interviewed by the dietitian for the details of nutritional status and alcohol intake. Nutritional status of the patients was classified as good, adequate or poor based on the daily caloric consumption, protein, carbohydrate, fat intake and vitamin supplements, according to protocol. The total duration and quantity (grams/day) of alcohol consumption were also noted. Clinical examination was carried out by the principle author (SP) with special emphasis placed on the peripheral nervous system. Motor strength was documented according to MRC scales; muscle stretch reflexes were recorded as hyperactive, normal, hypoactive or absent. Sensory testing of light touch and pain was carried out by conventional methods and recorded as normal, impaired, absent or hyperpathic. Vibration sensation was measured at the big toe at the metatarsal bone and the thumb at the metacarpal bone using a Biothesiometer (Bio-Medical Instruments Company, Newbury, Ohio, USA) producing a $100-120 \mathrm{HZ}$ sine wave vibration. Voltage applied at vibration threshold was measured from the voltmeter on a Biothesiometer by the method of limit converted to the amplitude and expressed as microns as described by Goldberg and Lindblom. ${ }^{19}$

\section{Electrophysiological studies}

Nerve conduction studies were carried out based on standard techniques. ${ }^{20}$ Skin tem- 
Table 1 Details of age and nutritional status of all the groups (SE)

\begin{tabular}{|c|c|c|c|c|c|c|c|}
\hline Groups & $\begin{array}{l}\text { Age } \\
\text { (Yrs) }\end{array}$ & $\begin{array}{l}\text { Weight } \\
\text { (Lbs) }\end{array}$ & $\begin{array}{l}\text { Total } \\
\text { calories }\end{array}$ & $\begin{array}{l}\text { Protein } \\
\text { (Grams) } \dagger\end{array}$ & $\begin{array}{l}\text { B } \\
\text { vitamins } \ddagger\end{array}$ & $\begin{array}{l}\text { Duration } \\
\text { of } \\
\text { drinking } \\
\text { (yrs) }\end{array}$ & $\begin{array}{l}\text { Average } \\
\text { daily } \\
\text { intake } \\
\text { (grams/day) }\end{array}$ \\
\hline $\begin{array}{l}\text { Controls } \\
\text { Disulfiram } 250 \mathrm{mg} \\
\text { Disulfiram } 125 \mathrm{mg}\end{array}$ & $\begin{array}{l}46(10) \\
42(9) \\
40(10)\end{array}$ & $\begin{array}{l}163(27) \\
169(25) \\
159(21)\end{array}$ & $\begin{array}{l}1850(450) \\
1925(495) \\
1790(500)\end{array}$ & $\begin{array}{l}64(8) \\
58(10) \\
60(12)\end{array}$ & $\begin{array}{l}\mathbf{A} \\
\mathbf{A} \\
\mathbf{A}\end{array}$ & $\begin{array}{l}26(10) \\
22(9) \\
23(8)\end{array}$ & $\begin{array}{l}207(25) \\
219(26) \\
230(18)\end{array}$ \\
\hline $\begin{aligned} \star \text { Calories } & >1800 \\
& 1800-1500 \\
& <1500\end{aligned}$ & $\begin{array}{l}\text { Good } \\
\text { Average } \\
\text { Poor }\end{array}$ & & & & & \multicolumn{2}{|c|}{$\begin{aligned} \text { †Protein } & >56 \mathrm{gm} \text { Good } \\
& 56 \mathrm{gm} \text { Average } \\
& <56 \mathrm{gm} \text { Poor }\end{aligned}$} \\
\hline \multicolumn{8}{|c|}{$\begin{array}{l}\text { †B Vitamins Good }(\mathrm{G})->2 \text { servings from meat group and } 4 \text { servings from grain group. } \\
\text { Average }(\mathrm{A})-2 \text { servings from meat plus } 4 \text { servings from grain group. } \\
\text { Poor }(\mathrm{P})-<2 \text { servings from meat or } 4 \text { servings from grain group. }\end{array}$} \\
\hline
\end{tabular}

perature was kept at $32-33^{\circ} \mathrm{C}$ over the testing area using a thermostatically controlled heating system (Dantec Type $15 \mathrm{HO} 2$ regulation unit). Dantec 1500 EMG system was used for the electrophysiological studies. Motor conduction studies were performed on median and peroneal nerves bilaterally. Distal latency, maximum conduction velocity and amplitude of the compound muscle action potentials were noted. Sensory nerve conduction studies were performed on median and sural nerves bilaterally and latency to the peak of the negative wave was recorded. Conduction velocity, amplitude and duration of the sensory nerve action potential were noted. A constant distance was used for all the conduction and latency studies. The tibialis-anterior muscle was investigated using a concentric needle electrode.

Spontaneous activities and motor unit analysis were performed using spike triggering and signal delay. Fifteen motor unit potentials were stored and mean duration and amplitude were measured and the percentage of polyphasic units were recorded.

The above base-line studies were performed within two weeks of admission. The subsequent testing in a similar fashion was repeated one, three and six months after starting disulfiram. The control group who were abstaining were also tested according to the same protocol. Forty-two disulfiram patients and 24 controls successfully completed the six months study. Investigators were blinded to the dosage of disulfiram until the end of the study.

\section{Results}

Clinical

Baseline clinical evaluation of the groups did not differ significantly (table 1). No overt symptoms of peripheral neuropathy were evident in any subjects. Absent ankle-jerk was recorded in two subjects in the control group and three in the disulfiram group. Normal

Table 2 Mean vibration threshold (microns)

\begin{tabular}{lclll}
\hline & Baseline & $M-1$ & $M-3$ & $M-6$ \\
\hline Control & 1.00 & 0.66 & 0.66 & 0.50 \\
Disulfiram 250 mg & 0.82 & 0.80 & $1.00 \mathrm{~A}$ & $1.20 \mathrm{C}$ \\
Disulfiram 125 mg & 1.00 & 0.82 & $0.82 \mathrm{~B}$ & $0.90 \mathrm{D}$ \\
\hline $\mathrm{A}=\mathrm{p}<0.05$ Disulfiram 250 mg vs control. & \\
$\mathrm{B}=\mathrm{p}<0.05$ Disulfiram 125 mg vs control. & \\
$\mathrm{C}=\mathrm{p}<0.001$ Disulfiram 250 mg vs control. & \\
D $=\mathrm{p}<0.01$ Disulfiram 125 mg vs control.
\end{tabular}

muscle strength and touch and pain sensation were noted in all subjects. Nine out of 42 subjects in the disulfiram group, took only $125 \mathrm{mg}$ of disulfiram daily because of reported drowsiness with $250 \mathrm{mg}$ whereas, the other 33 were on $250 \mathrm{mg}$ per day. These two groups were analysed separately.

None of the subjects developed any acute or subacute symptoms of peripheral neuropathy during the six month study period. There was no change in either muscle strength and reflexes, or touch and pain sensation. The data for vibration perception were analysed by repeated measure analyses of variance. No significant initial differences were observed between the three groups. However, there were statistically significant differences at the third and sixth months of observation between groups (table 2). Interestingly, there was a significant improvement within the control group itself between the first and the last observation period $(p<0.001)$.

\section{Electrophysiological studies}

The data were analysed by a repeated measures analysis of variance with groups and months of observation as the independent variables. The dependent measures were: (1) distal latency (median and peroneal); (2) motor nerve conduction velocity (median and peroneal); (3) sensory nerve conduction velocity (median and sural); (4) amplitude of compound muscle and nerve action potentials; (5) duration of sensory nerve action potentials. All analyses were performed using a Greenhouse-Geisser (1959)

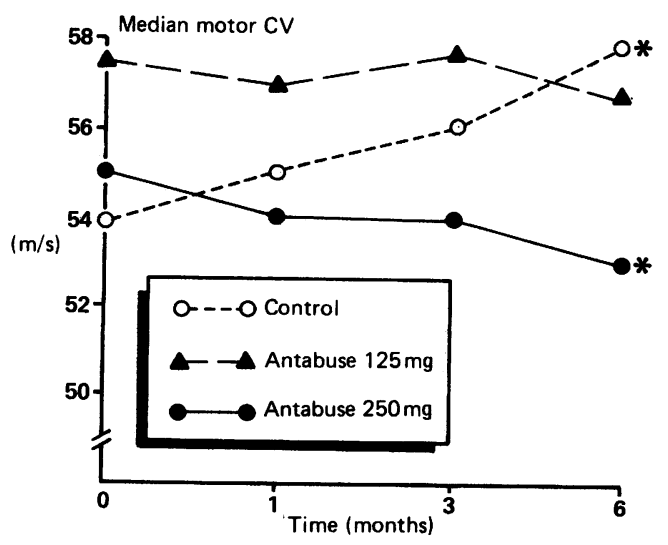

Figure 1 Change in median motor conduction velocity over months. ${ }^{\star}=P<0.05$ component change within group over six months of observation. $A=P<0.05$ $250 \mathrm{mg}$ disulfiram versus control. 
Figure 2 Change in peroneal conduction velocity over months. $\star=P<0.01$ component change within group over six months of observation. $A=P<0.01250 \mathrm{mg}$ disulfiram versus control.
Figure 3 Change in median sensory conduction velocity over months. $\star=P<0.01$ component change within group over six months of observation. $A=P<0.001250 \mathrm{mg}$ disulfiram versus control. $B=P<0.05250 \mathrm{mg}$ disulfiram versus $125 \mathrm{mg}$ disulfiram.

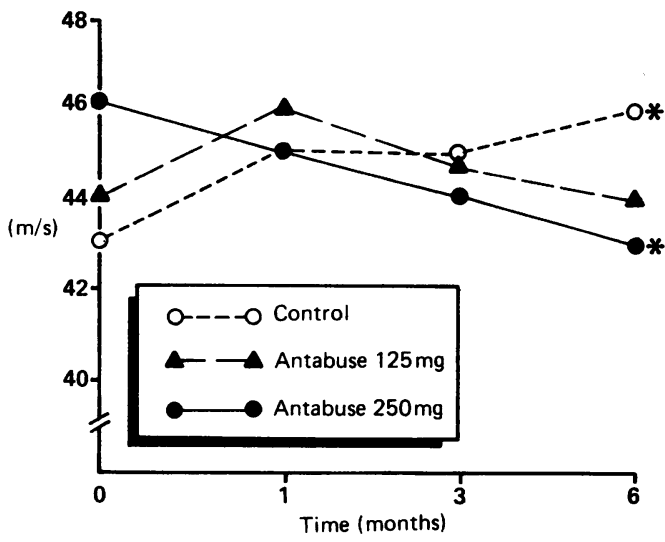

adjustment to the degrees of freedom to protect against type-1 errors. Subsequent analyses employing the Duncan range test were conducted on each interaction.

The analyses revealed significant changes over the six months for median motor conduction velocity $\times$ groups $(p<0.001)$, median motor latency $(p=0.045)$, peroneal conduction velocity $(p<0.001)$, median sensory velocity $(p=0.0004)$ and amplitude ( $p=0.002)$, as well as sural sensory conduction velocity $(p=0.007)$. Trends were observed at several periods of observation, however figures 1 to 4 respectively show the significant differences between groups at the last observation period in peroneal, median and sural conduction velocity.

Peroneal conduction velocity for the $250 \mathrm{mg}$ disulfiram group significantly declined, while the control group significantly increased $(p<0.01)$ over six months observation. Significant differences were observed between the $250 \mathrm{mg}$ disulfiram group and the controls $(\mathrm{p}<0.01)$. This reflects the divergence in conduction velocity by the control and $250 \mathrm{mg}$ disulfiram group; the former increased and the latter decreased in conduction velocity.

Needle EMG of the tibialis-anterior muscle was carried out in all the groups and spontaneous activities and motor unit analyses were performed during each visit. Abnormal spontaneous activity, that is, fibrillation and positive sharp waves of mild degree were seen in three of $250 \mathrm{mg}$ disulfiram group at six months.

A $3 \times 4$ repeated measure analysis of variance was conducted on amplitude, duration of motor unit potential and percentage of

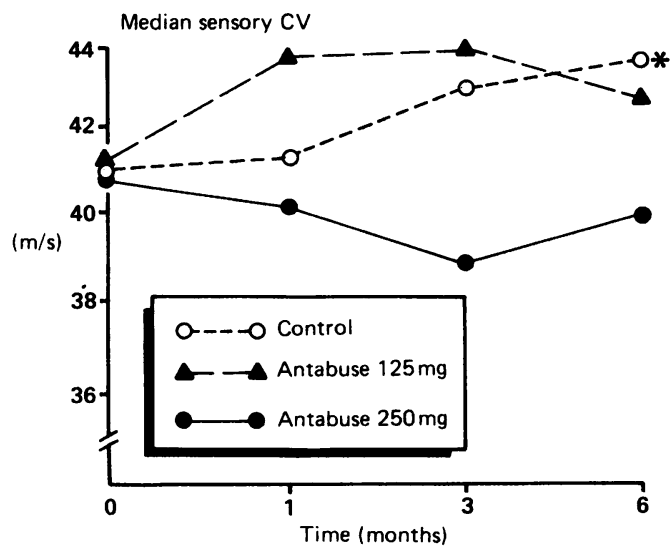

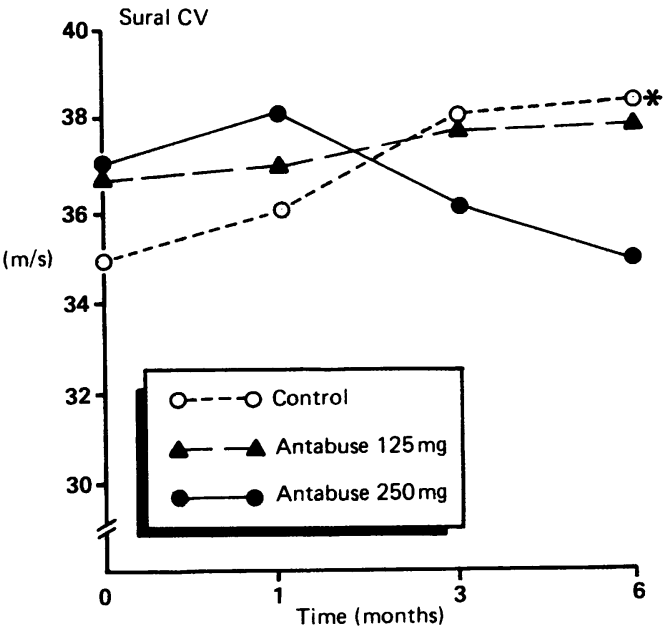

Figure 4 Change in sural sensory conduction over months. $\star=P<0.05$ component change within group over six months of observation. $A=P<0.05250 \mathrm{mg}$ disulfiram versus control. $B=P<0.05250 \mathrm{mg}$ disulfiram versus $125 \mathrm{mg}$ disulfiram.

polyphasic motor unit potential. The groups differed significantly over months for the polyphasic measure $(\mathrm{p}<0.001)$ and are presented in Table 3.

\section{Discussion}

Our data show that there is either no change or a gradual decline in peripheral nerve functions in chronic alcoholic patients when treated with disulfiram. This decline is most likely due to a direct effect of disulfiram as these patients were abstinent throughout the study period and had no other predisposing factors for peripheral neuropathy. Also, our controls were observed on several components to reverse or improve. Though statistically significant difference in conduction velocities was seen at six months when compared to the baseline values, a trend in decline of conduction velocity was obvious by three months. This agrees with our previous findings on 15 chronic alcoholic patients on $250 \mathrm{mg}$ of disulfiram. ${ }^{18}$

In our experience, the dosage of disulfiram appears to have a role in the degree of peripheral nerve dysfunction. The subjects on $125 \mathrm{mg}$ of disulfiram showed no change in the nerve conduction parameters from baseline through to the end of the study. The case of disulfiram neuropathy reported by Worner ${ }^{21}$ showed that peripheral neuropathy improved despite continuing disulfiram at a lower dose of $125 \mathrm{mg}$. It has been suggested that the dose of disulfiram should not exceed $200 \mathrm{mg}$ daily. ${ }^{11}$ Feldman $^{22}$ treated his patients with $125 \mathrm{mg}$ and none developed peripheral neuropathy after

Table 3 Mean polyphasic motor units (percentage)

\begin{tabular}{|c|c|c|c|c|}
\hline & Baseline & $\begin{array}{l}\text { First } \\
\text { month }\end{array}$ & $\begin{array}{l}\text { Third } \\
\text { month }\end{array}$ & $\begin{array}{l}\text { Sixth } \\
\text { month }\end{array}$ \\
\hline $\begin{array}{l}\text { Control } \\
\text { Disulfiram } 250 \mathrm{mg} \\
\text { Disulfiram } 125 \mathrm{mg}\end{array}$ & $\begin{array}{l}20 \cdot 22 \\
24 \cdot 54 \\
18 \cdot 88\end{array}$ & $\begin{array}{l}25 \cdot 90 \\
23 \cdot 33 \\
14 \cdot 44 \mathrm{~B}\end{array}$ & $\begin{array}{l}28 \cdot 5 \\
18 \cdot 93 \mathrm{~A} \\
18 \cdot 33 \mathrm{~B}\end{array}$ & $\begin{array}{l}30 \cdot 27^{\star} \\
16 \cdot 77 \mathrm{~A} \\
16 \cdot 66 \mathrm{~B}\end{array}$ \\
\hline
\end{tabular}

$\mathrm{A}=\mathrm{p}<0.05250 \mathrm{mg}$ Disulfiram vs control.

$\mathrm{B}=\mathrm{p}<0.05125 \mathrm{mg}$ Disulfiram vs control.

$\star=p<0.05$ Increase in polyphasic motor units cell mean over six months. 
continuous use for two years. All the cases of disulfiram neuropathy reported in the literature were on $250 \mathrm{mg}$ or higher. Fulminant polyneuritis after an overdose of disulfiram and alcohol has also been reported. ${ }^{15}$ Thus, we believe that disulfiram at a dose of $125 \mathrm{mg}$ or lower may be a safer level to use.

During a six month period none of our experimental group developed any acute or subacute symptoms of peripheral neuropathy. This contrasts with several case reports in the literature. Most of the patients developed the symptoms within two to three months of disulfiram treatment..$^{591213}$ In some cases, treatment with higher doses, alcohol disulfiram reaction, concomitant use of other drugs and a preexisting alcohol/nutritional neuropathy appear to have contributed to earlier and acute symptoms of neuropathy. ${ }^{1011116}$ Possibly, the strict inclusion criteria used in this study is associated with the failure to observe symptoms of peripheral neuropathy. Consequently, a thorough neurological examination with emphasis on peripheral nervous system, serial electrodiagnostic studies and a close follow up evaluation would assist in the reduction of disulfiram induced neuropathy.

An interesting finding of this study is the gradual improvement in the peripheral nerve function of the electrophysiological parameters in the control group, (that is, alcoholics abstaining without disulfiram). The needle electromyography study showed a significant increase $(p<0.01)$ in the amount of polyphasic motor units suggesting an ongoing electrophysiological improvement at the intramuscular nerve level. This observation needs further study to determine the natural course of alcoholic peripheral neuropathy, as the literature on this is scanty. Hillbom and Wennberg $^{23}$ reported seven of ten patients with alcoholic neuropathy showing improvement when re-examined after three to five years. But 11 patients of Hawley, et al, ${ }^{24}$ had no electrophysiological improvement in six months.

Our study shows that there is a clear subclinical decline in peripheral nerve functions within six months of disulfiram treatment with $250 \mathrm{mg}$ daily. Since no significant changes occur with $125 \mathrm{mg}$ it seems logical to treat chronic alcoholic patients with $125 \mathrm{mg}$ disulfiram when necessary, to reduce the toxic effect on peripheral nerves.

We thank Dr DM Gallant and his staff in the
Alcohol Rehabilitation Unit for their cooperation, B Moore and R Bauman for technical help, Dr S Ganji for reviewing the manuscript, $\mathrm{K}$ Soule and $\mathrm{T}$ Andrues for secretarial help and those patients who participated in this study.

This project was fully supported by a grant from the Merit Review Board of the Veterans Administration.

1 Child GP, Osinski W, Bennet RE, Davidoff E. Therapeutic results and chemical manifestations following the use of tetraethyl-thiuram disulfide (Antabuse). Am J Psychiatry 1951;107:774-80.

2 Charaten FB. Peripheral Neuritis following tetraethylthiuram disulfide treatment. Br Med J 1953;2:380.

3 Dallessio DJ. Peripheral neuropathy associated with disulfiram (Antabuse) therapy. Bull Los Angeles Neurol So 1968;33:136-9.

4 Marra TR. Disulfiram Neuropathy. Wis Med J 1981;80: 29-30.

5 Olney RK, Miller RG. Peripheral neuropathy associated with disulfiram administration. Muscle Nerve 1980;3: $172-5$

6 Mokri B, Ohnishi A, Dyck PJ. Disulfiram Neuropathy. Neurol 1981;31:730-5.

7 Norris FH. Neuropathy associated with disulfiram administration. Arch Neurol 1979;36:386-7.

8 Moddel G, Bilbao J, Payne D, Ashby P. Disulfiram neuropathy. Arch Neurol 1978;35:658-60.

9 Watson CP, Ashby P, Bilbao JM. Disulfiram neuropathy. Can Med Assoc J 1980;123:123-6.

10 Nukada H, Pollock M. Disulfiram neuropathy. A morphometric study of sural nerve. J Neurol Sci 1981;51: 51-67.

11 Gardner-Thorpe C, Benjamin S. Peripheral neuropathy after disulfiram administration. J Neurol Neurosurg Psychiatry 1971;34:253-9.

12 Hayman M, Wilkins PA. Polyneuropathy as a complication of disulfiram therapy of alcoholism. Quart J Stud Alcohol 1956;17:601-7.

13 Bradley WG, Hewer RL. Peripheral neuropathy due to disulfiram. Br Med J 166;2:449-50.

14 Bilbao JM, Briggs SJ, Gray TA. Filamentous axonopathy in disulfiram neuropathy. Ultrastruct Pathol 1984;7 295-300

15 Rothrock JF, Johnson PC, Rothrock S, Merkley R. Fulminant polyneuritis after overdose of disulfiram and ethanol. Neurol 1984;34:357-9.

16 Van Rossum, Roos RAC, Bots G TH AM. Disulfiram polyneuropathy. Clin Neurol Neurosurg 1984;86:81-7.

17 Anzil AP, Dozic S. Disulfiram neuropathy: An experimenta study in the rat. J Neuropath Exp Neurol 1978;37:583.

18 Palliyath S, Schwartz BD. Disulfiram neuropathy: electrophysiological study. Electromyogr Clin Neurophysiol 1988; 28:245-7.

19 Goldberg JM, Linblom U. Standardised method of determining vibratory perception thresholds for diagnosis and screening in neurological investig

Neurosurg Psychiatry 1979;42:793-803.
20 Oh SJ. Clinical electromyography, nerve conduction studies. Baltimore: University Park Press, 1984

21 Worner TM. Peripheral neuropathy after disulfiram administration: reversibility despite continued therapy. Drug Alcohol Depend 1982;26:67-76.

22 Feldman DS. Drug Therapy of chronic alcoholism. Med Clin N Amer 1957;41:381-92.

23 Hillbom M, Wennberg A. Prognosis of alcoholic peripheral neuropathy. J Neurol Neurosurg Psychiatry 1984;47 699-703.

24 Hawley RJ, Kurtzke JF, Armbrustmacher VW, Saini N, Manz H. The course of alcoholic nutritional peripheral neuropathy. Acta Neurol Scandinav 1982;66:582-9. 